\title{
STAGNATION-POINT FLOW OF THE WALTERS' B' FLUID WITH SLIP
}

\author{
F. LABROPULU, I. HUSAIN, and M. CHINICHIAN
}

Received 25 June 2004

\begin{abstract}
The steady two-dimensional stagnation point flow of a non-Newtonian Walters' B' fluid with slip is studied. The fluid impinges on the wall either orthogonally or obliquely. A finite difference technique is employed to obtain solutions.
\end{abstract}

2000 Mathematics Subject Classification: 65L06, 65L12, 76D05.

1. Introduction. Some rheologically complex fluids such as polymer solutions, blood, paints, and certain oils cannot be adequately described by the Navier-Stokes theory. For this reason, several theories of non-Newtonian fluids were developed. One important and useful model which has been used to describe the non-Newtonian behavior exhibited by certain fluids is the Walters' B' fluid [16]. The equations of motion of non-Newtonian fluids are highly nonlinear and one order higher than the Navier-Stokes equations. Due to the complexity of these equations, finding accurate solutions is not easy.

One class of flows which has received considerable attention is stagnation-point flow. In a stagnation-point flow of a Newtonian fluid, a rigid wall occupies the entire $x$-axis, the fluid domain is $y>0$, and the flow impinges on the wall either orthogonally [6, 7] or obliquely $[4,14,15]$. In a study of Newtonian fluid impinging on a flat rigid wall obliquely, Dorrepaal [4] found that the slope of the dividing streamline at the wall divided by its slope at infinity is independent of the angle of incidence. Beard and Walters [2] used boundary-layer equations to study two-dimensional flow near a stagnation point of a viscoelastic fluid. Rajagopal et al. [11] have studied the Falkner-Skan flows of an incompressible second grade fluid. Dorrepaal et al. [5] investigated the behavior of a viscoelastic fluid impinging on a flat rigid wall at an arbitrary angle of incidence. Labropulu et al. [9] studied the oblique flow of a second grade fluid impinging on a porous wall with suction or blowing.

In a recent paper, Wang [17] studied stagnation-point flows with slip. This problem appears in some applications where a thin film of light oil is attached to the plate or when the plate is coated with special coatings such as a thick monolayer of hydrophobic octadecyltrichlorosilane [3]. Also, wall slip can occur if the working fluid contains concentrated suspensions [13].

When the molecular mean free path length of the fluid is comparable to the system's characteristic length, then rarefaction effects must be considered. The Knudsen number $K_{n}$, defined as the ratio of the molecular mean free path to the characteristic length of the system, is the parameter used to classify fluids that deviate from continuum 
behavior. If $K_{n}>10$, it is free molecular flow, if $0.1<K_{n}<10$, it is transition flow, if $0.01<K_{n}<0.1$, it is slip flow, and if $K_{n}<0.01$, it is viscous flow (see Wang [17], Kogan [8]). Flows in the slip-flow region have been modeled using the Navier-Stokes equations and the traditional nonslip condition is replaced by the slip condition

$$
u_{t}=A_{p} \frac{\partial u_{t}}{\partial n}
$$

where $u_{t}$ is the tangential velocity component, $n$ is normal to the plate, and $A_{p}$ is a coefficient close to 2 (mean free path) $/ \sqrt{\pi}$ (see Sharipov and Seleznev [12]). This condition was first proposed by Navier [10] nearly two hundred years ago.

In the present study, we follow Wang [17] and investigate the behavior of the Walters' B' fluid impinging on a rigid wall with slip. The fluid impinges on the wall either orthogonally or obliquely. In particular, we study the effects of the slip condition and the effects of viscoelasticity of the fluid.

2. Flow equations. The two-dimensional flow of a viscous incompressible nonNewtonian Walters' B' fluid, neglecting thermal effects and body forces, is governed by (see Beard and Walters [2]):

$$
\begin{gathered}
\frac{\partial u^{*}}{\partial x^{*}}+\frac{\partial v^{*}}{\partial y^{*}}=0, \\
u^{*} \frac{\partial u^{*}}{\partial x^{*}}+v^{*} \frac{\partial u^{*}}{\partial y^{*}}+\frac{1}{\rho} \frac{\partial p^{*}}{\partial x^{*}} \\
=v \nabla^{* 2} u^{*}-\frac{\alpha}{\rho}\left\{\left(u^{*} \frac{\partial}{\partial x^{*}}+v^{*} \frac{\partial}{\partial y^{*}}\right) \nabla^{2} u^{*}-\frac{\partial u^{*}}{\partial x^{*}} \nabla^{2} u^{*}-\frac{\partial u^{*}}{\partial y^{*}} \nabla^{2} v^{*}\right. \\
-2\left[\frac{\partial u^{*}}{\partial x^{*}} \frac{\partial^{2} u^{*}}{\partial x^{* 2}}+\frac{\partial v^{*}}{\partial y^{*}} \frac{\partial^{2} u^{*}}{\partial y^{* 2}}+\left(\frac{\partial u^{*}}{\partial y^{*}}+\frac{\partial v^{*}}{\partial x^{*}}\right) \frac{\partial^{2} u^{*}}{\left.\left.\partial x^{*} \partial y^{*}\right]\right\},}\right. \\
u^{*} \frac{\partial v^{*}}{\partial x^{*}}+v^{*} \frac{\partial v^{*}}{\partial y^{*}}+\frac{1}{\rho} \frac{\partial p^{*}}{\partial y^{*}} \\
=v \nabla^{* 2} v^{*}-\frac{\alpha}{\rho}\left\{\left(u^{*} \frac{\partial}{\partial x^{*}}+v^{*} \frac{\partial}{\partial y^{*}}\right) \nabla^{2} v^{*}-\frac{\partial v^{*}}{\partial x^{*}} \nabla^{2} u^{*}-\frac{\partial v^{*}}{\partial y^{*}} \nabla^{2} v^{*}\right. \\
\left.-2\left[\frac{\partial u^{*}}{\partial x^{*}} \frac{\partial^{2} v^{*}}{\partial x^{* 2}}+\frac{\partial v^{*}}{\partial y^{*}} \frac{\partial^{2} v^{*}}{\partial y^{* 2}}+\left(\frac{\partial u^{*}}{\partial y^{*}}+\frac{\partial v^{*}}{\partial x^{*}}\right) \frac{\partial^{2} v^{*}}{\partial x^{*} \partial y^{*}}\right]\right\},
\end{gathered}
$$

where $u^{*}=u^{*}\left(x^{*}, y^{*}\right), v^{*}=v^{*}\left(x^{*}, y^{*}\right)$ are the velocity components, $p^{*}=p^{*}\left(x^{*}, y^{*}\right)$ is the pressure, $v=\mu / \rho$ is the kinematic viscosity, and $\alpha$ is the viscoelasticity of the fluid. The star on a variable indicates its dimensional form. We nondimensionalize the above equations according to

$$
\begin{gathered}
x=x^{*} \sqrt{\frac{\beta}{v}}, \quad y=y^{*} \sqrt{\frac{\beta}{v}} \\
u=\frac{1}{\sqrt{v \beta}} u^{*}, \quad v=\frac{1}{\sqrt{v \beta}} v^{*}, \quad p=\frac{1}{\rho v \beta} p^{*},
\end{gathered}
$$


where $\beta$ has the units of inverse time. The flow equations in nondimensional form are

$$
\begin{aligned}
& \frac{\partial u}{\partial x}+\frac{\partial v}{\partial y}=0 \\
u \frac{\partial u}{\partial x}+v \frac{\partial u}{\partial y}+\frac{\partial p}{\partial x}=\nabla^{2} u-W_{e}\{ & \left(u \frac{\partial}{\partial x}+v \frac{\partial}{\partial y}\right) \nabla^{2} u-\frac{\partial u}{\partial x} \nabla^{2} u-\frac{\partial u}{\partial y} \nabla^{2} v \\
& \left.-2\left[\frac{\partial u}{\partial x} \frac{\partial^{2} u}{\partial x^{2}}+\frac{\partial v}{\partial y} \frac{\partial^{2} u}{\partial y^{2}}+\left(\frac{\partial u}{\partial y}+\frac{\partial v}{\partial x}\right) \frac{\partial^{2} u}{\partial x \partial y}\right]\right\} \\
u \frac{\partial v}{\partial x}+v \frac{\partial v}{\partial y}+\frac{\partial p}{\partial y}=\nabla^{2} v-W_{e}\{ & \left(u \frac{\partial}{\partial x}+v \frac{\partial}{\partial y}\right) \nabla^{2} v-\frac{\partial v}{\partial x} \nabla^{2} u-\frac{\partial v}{\partial y} \nabla^{2} v \\
- & \left.2\left[\frac{\partial u}{\partial x} \frac{\partial^{2} v}{\partial x^{2}}+\frac{\partial v}{\partial y} \frac{\partial^{2} v}{\partial y^{2}}+\left(\frac{\partial u}{\partial y}+\frac{\partial v}{\partial x}\right) \frac{\partial^{2} v}{\partial x \partial y}\right]\right\}
\end{aligned}
$$

where $W_{e}$ is the Weissenberg number.

Continuity equation (2.3) implies the existence of a streamfunction $\psi(x, y)$ such that

$$
u=\frac{\partial \psi}{\partial y}, \quad v=-\frac{\partial \psi}{\partial x} .
$$

Substitution of (2.6) in (2.4) and (2.5) and elimination of pressure from the resulting equations using $p_{x y}=p_{y x}$ yields

$$
\frac{\partial\left(\psi, \nabla^{2} \psi\right)}{\partial(x, y)}+W_{e} \frac{\partial\left(\psi, \nabla^{4} \psi\right)}{\partial(x, y)}+\nabla^{4} \psi=0
$$

Having obtained a solution of (2.7), the velocity components are given by (2.6) and the pressure can be found by integrating (2.4) and (2.5).

The shear stress component $\tau_{12}$ is given by

$$
\begin{gathered}
\tau_{12}=\mu \beta\left\{\left[\frac{\partial^{2} \psi}{\partial y^{2}}-\frac{\partial^{2} \psi}{\partial x^{2}}\right]-W_{e}\left[\frac{\partial \psi}{\partial y}\left(\frac{\partial^{3} \psi}{\partial x \partial y^{2}}-\frac{\partial^{3} \psi}{\partial x^{3}}\right)-\frac{\partial \psi}{\partial x}\left(\frac{\partial^{3} \psi}{\partial y^{3}}-\frac{\partial^{3} \psi}{\partial x^{2} \partial y}\right)\right.\right. \\
\left.\left.+2 \frac{\partial^{2} \psi}{\partial x \partial y} \frac{\partial^{2} \psi}{\partial y^{2}}+2 \frac{\partial^{2} \psi}{\partial x^{2}} \frac{\partial^{2} \psi}{\partial x \partial y}\right]\right\} .
\end{gathered}
$$

3. Orthogonal flow. We assume that the infinite plate is at $y=0$ and that the fluid occupies the entire upper half-plane $y>0$. Furthermore, we assume that the streamfunction far from the wall is given by $\psi=x y$ (see Hiemenz [7]). Thus, the nondimensional boundary conditions are given by

$$
\frac{\partial \psi}{\partial x}=0 \quad \text { at } y=0, \quad \psi(x, y) \sim y \quad \text { as } y \rightarrow \infty .
$$

The slip condition in (1.1) is

$$
\frac{\partial \psi}{\partial y}=\gamma \frac{\partial^{2} \psi}{\partial y^{2}}
$$

where $\gamma=A_{p} \sqrt{\beta} v$ is a parameter representing the slip to viscous effects. 
TABLE 3.1. Numerical values of $F^{\prime \prime}(0)$ for various values of $W_{e}$ and $\gamma$.

\begin{tabular}{l|cccc}
\hline$\gamma$ & \multicolumn{3}{|c}{$W_{e}$} \\
& 0 & 0.1 & 0.2 & 0.3 \\
\hline 0 & 1.23259 & 1.36954 & 1.58730 & 2.11092 \\
0.2 & 1.04258 & 1.14323 & 1.29803 & 1.63401 \\
0.4 & 0.88634 & 0.95916 & 1.06657 & 1.27238 \\
0.6 & 0.76428 & 0.81807 & 0.89459 & 1.02828 \\
0.8 & 0.66896 & 0.70984 & 0.76634 & 0.85879 \\
1 & 0.59346 & 0.62537 & 0.66850 & 0.73581 \\
2 & 0.37588 & 0.38834 & 0.40415 & 0.42609 \\
5 & 0.17726 & 0.17995 & 0.18319 & 0.18731 \\
10 & 0.09402 & 0.094776 & 0.09565 & 0.09674 \\
20 & 0.04847 & 0.04866 & 0.04889 & 0.04917 \\
\hline
\end{tabular}

Following Wang [17], we assume that

$$
\psi=x F(y)
$$

Using (3.3) in (2.7) and the boundary conditions (3.1) and (3.2), we obtain

$$
\begin{aligned}
& F^{(i v)}+F F^{\prime \prime \prime}-F^{\prime} F^{\prime \prime}+W_{e}\left(F F^{(v)}-F^{\prime} F^{(i v)}\right)=0, \\
& F(0)=0, \quad F^{\prime}(0)=\gamma F^{\prime \prime}(0), \quad F^{\prime}(\infty)=0,
\end{aligned}
$$

where the prime denotes differentiation with respect to $y$. Integration of (3.4) once with respect to $y$ and use of the condition at infinity yields

$$
\begin{gathered}
F^{\prime \prime \prime}+F F^{\prime \prime}-F^{\prime 2}+W_{e}\left(F F^{(i v)}-2 F^{\prime} F^{\prime \prime \prime}+F^{\prime \prime 2}\right)=-1, \\
F(0)=0, \quad F^{\prime}(0)=\gamma F^{\prime \prime}(0), \quad F^{\prime}(\infty)=0 .
\end{gathered}
$$

The above system with $\gamma=0$ has been solved by many authors for various values of $W_{e}$ (see Beard and Walters [2], Ariel [1]). When $W_{e}=0$, the above system has been solved numerically by Wang [17] for various values of $\gamma$. Using the shooting method with the finite difference technique described by Ariel [1], we find that $F^{\prime \prime}(0)=1.23259$ when $W_{e}=0$ and $\gamma=0$. Numerical values of $F^{\prime \prime}(0)$ for different values of $W_{e}$ and $\gamma$ are shown in Table 3.1. Figure 3.1 shows the profiles of $F^{\prime}$ for $\gamma=0$ and various values of $W_{e}$. Figure 3.2 depicts the profiles of $F^{\prime}$ for $\gamma=1$ and various values of $W_{e}$. Figure 3.3 shows the profiles of $F^{\prime}$ for $W_{e}=0.2$ and various values of $\gamma$. Figure 3.4 depicts the profiles of $F$ for $W_{e}=0.2$ and various values of $\gamma$. We observe that as the elasticity of the fluid increases, the velocity near the wall increases and as the slip parameter $\gamma$ increases the velocity near the wall increases as well.

For large $y$, we find that

$$
F \approx y+C
$$




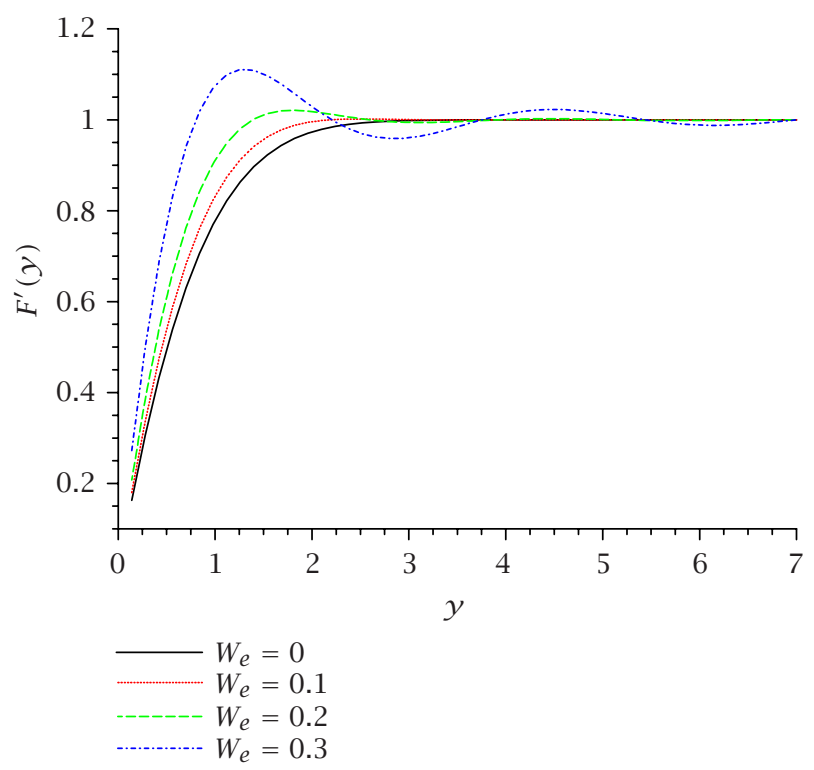

FIGURE 3.1. Variation of $F^{\prime}(y)$ for $\gamma=0$ and various values of $W_{e}$.

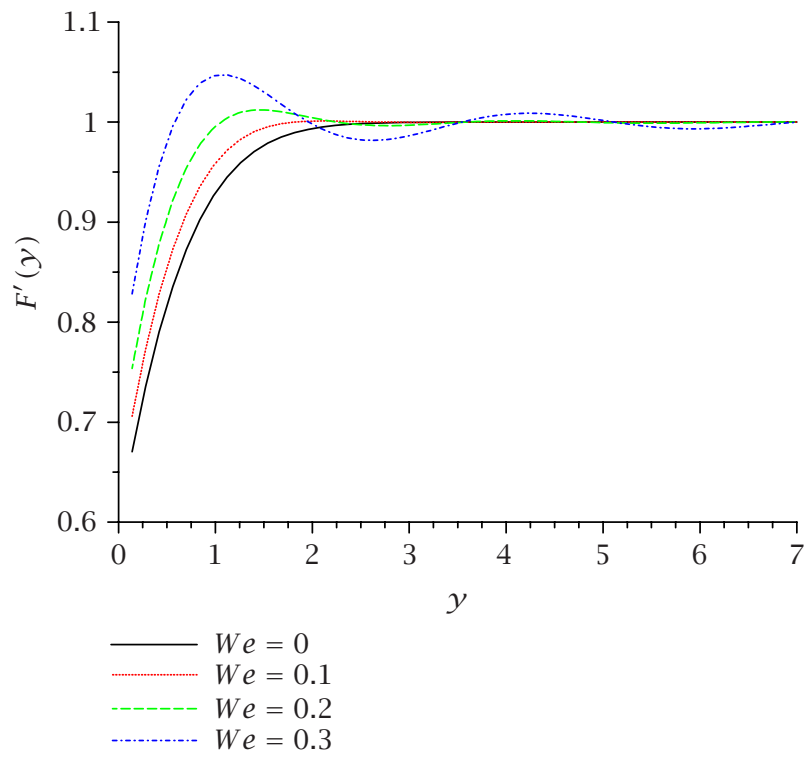

FIGURE 3.2. Variation of $F^{\prime}(y)$ for $\gamma=1$ and various values of $W_{e}$.

where the numerical values of $C$ are shown in Table 3.2 for various values of $W_{e}$ and $\gamma$. The numerical results are in good agreement with those of Wang [17] if $W_{e}=0$ and those of Ariel [1] if $\gamma=0$. 


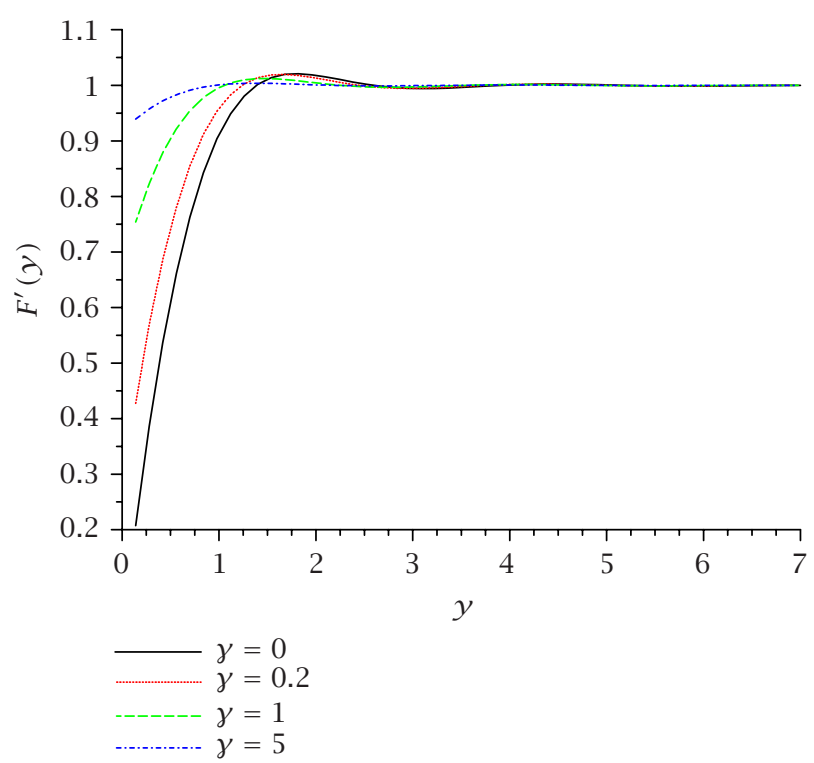

FIGURE 3.3. Variation of $F^{\prime}(y)$ for $W_{e}=0.2$ and various values of $\gamma$.

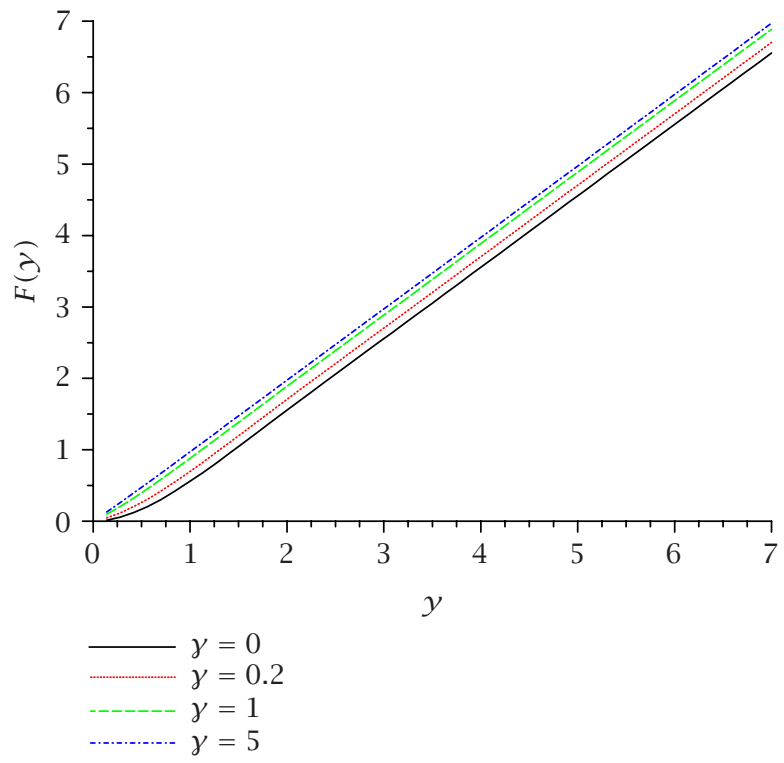

FIGURE 3.4. Variation of $F(y)$ for $W_{e}=0.2$ and various values of $\gamma$. 
TABLE 3.2. Numerical values of $C$ for various values of $W_{e}$ and $\gamma$.

\begin{tabular}{l|cccc}
\hline$\gamma$ & \multicolumn{3}{|c}{$W_{e}$} \\
& 0 & 0.1 & 0.2 & 0.3 \\
\hline 0 & -0.65086 & -0.55952 & -0.44641 & -0.26445 \\
0.2 & -0.49199 & -0.40368 & -0.29665 & -0.13110 \\
0.4 & -0.39045 & -0.30926 & -0.21462 & -0.08016 \\
0.6 & -0.32210 & -0.24848 & -0.16585 & -0.05625 \\
0.8 & -0.27359 & -0.20683 & -0.13433 & -0.04289 \\
1 & -0.23757 & -0.17677 & -0.11255 & -0.03449 \\
2 & -0.14297 & -0.10161 & -0.06152 & -0.01716 \\
5 & -0.06513 & -0.04433 & -0.02583 & -0.00675 \\
10 & -0.03416 & -0.02282 & -0.01311 & -0.00334 \\
20 & -0.01752 & -0.01157 & -0.00660 & -0.00166 \\
\hline
\end{tabular}

The Maclaurin series expansion for $F(y)$ is given by

$$
F(y)=\gamma s y+\frac{1}{2} s y^{2}-\frac{1}{6} \frac{1+W_{e} s^{2}-\gamma^{2} s^{2}}{1-2 W_{e} \gamma s} y^{3},
$$

where the values of $F^{\prime \prime}(0)=s$ are given in Table 3.1.

4. Oblique flow. Following Stuart [14], we assume that the streamfunction far from the wall is given by

$$
\psi(x, y) \sim k y^{2}+x y,
$$

where $k$ is a constant. The dividing streamline which comes from the wall from infinity is defined by $\psi(x, y)=0$ and its slope at infinity is $-1 / k$. Equation (4.1) suggests that $\psi(x, y)$ has the form

$$
\psi(x, y)=x F(y)+G(y) .
$$

The boundary conditions for $F(y)$ and $G(y)$ are

$$
\begin{aligned}
& F(0)=0, \quad F^{\prime}(0)=\gamma F^{\prime \prime}(0), \quad G(0)=0, \quad G^{\prime}(0)=\gamma G^{\prime \prime}(0), \\
& F(y) \sim y, \quad G(y) \sim k y^{2} \text { as } y \longrightarrow \infty .
\end{aligned}
$$

Employing (4.2) in (2.7), we obtain an equation which contains terms of $O(x)$ and $O(1)$. The terms of $O(x)$ yield an ordinary differential equation for $F(y)$ and the terms of $O$ (1) yield an equation for $G(y)$.

After one integration the boundary-value problem for $F(y)$ is

$$
\begin{gathered}
F^{\prime \prime \prime}+F F^{\prime \prime}-F^{\prime 2}+W_{e}\left(F F^{(i v)}-2 F^{\prime} F^{\prime \prime \prime}+F^{\prime \prime 2}\right)=-1, \\
F(0)=0, \quad F^{\prime}(0)=\gamma F^{\prime \prime}(0), \quad F^{\prime}(\infty)=1 .
\end{gathered}
$$

Numerical solutions of this system were obtained in the previous section for various values of $W_{e}$ and $\gamma$. 
TABLE 4.1. Numerical values of $H^{\prime}(0)$ for various values of $W_{e}$ and $\gamma$.

\begin{tabular}{l|cccc}
\hline$\gamma$ & \multicolumn{3}{|c}{$W_{e}$} \\
& 0 & 0.1 & 0.2 & 0.3 \\
\hline 0 & 1.40651 & 1.46151 & 1.55278 & 1.70295 \\
0.2 & 1.09256 & 1.11018 & 1.14278 & 1.18676 \\
0.4 & 0.87851 & 0.87714 & 0.88073 & 0.87935 \\
0.6 & 0.72934 & 0.71877 & 0.70902 & 0.69089 \\
0.8 & 0.62139 & 0.60642 & 0.59064 & 0.56662 \\
1 & 0.54037 & 0.52337 & 0.50500 & 0.47934 \\
2 & 0.32534 & 0.30824 & 0.29044 & 0.26913 \\
5 & 0.14793 & 0.13698 & 0.12677 & 0.11561 \\
10 & 0.07757 & 0.07100 & 0.06527 & 0.05919 \\
20 & 0.03977 & 0.03615 & 0.03311 & 0.02995 \\
\hline
\end{tabular}

The boundary-value problem for $G(y)$ is given by

$$
\begin{gathered}
G^{(i v)}+F G^{\prime \prime \prime}-F^{\prime \prime} G^{\prime}+W_{e}\left(F G^{(v)}-F^{(i v)} G^{\prime}\right)=0, \\
G(0)=0, \quad G^{\prime}(0)=\gamma G^{\prime \prime}(0), \quad G^{\prime}(\infty)=2 k y .
\end{gathered}
$$

Integration of (4.5) once with respect to $y$ using the conditions at infinity yields

$$
G^{\prime \prime \prime}+F G^{\prime \prime}-F^{\prime} G^{\prime}+W_{e}\left(F G^{(i v)}-F^{\prime} G^{\prime \prime \prime}+F^{\prime \prime} G^{\prime \prime}-F^{\prime \prime \prime} G^{\prime}\right)=2 k C,
$$

where the values of $C$ are given in Table 3.2.

Letting $G^{\prime}(y)=2 k H(y)$, we obtain

$$
H^{\prime \prime}+F H^{\prime}-F^{\prime} H+W_{e}\left(F H^{\prime \prime \prime}-F^{\prime} H^{\prime \prime}+F^{\prime \prime} H^{\prime}-F^{\prime \prime \prime} H\right)=C .
$$

The boundary conditions for $H(y)$ are

$$
H(0)=\gamma H^{\prime}(0), \quad H^{\prime}(\infty)=1 .
$$

Equation (4.8) with boundary conditions (4.9) is solved numerically using the same numerical technique as in the previous section. The numerical values of $H^{\prime}(0)$ are given in Table 4.1 for various values of $W_{e}$ and $\gamma$. These values are in good agreement with those obtained by Wang [17] for $W_{e}=0$. Figure 4.1 shows the profiles of $H^{\prime}$ for $\gamma=1$ and various values of $W_{e}$. Figure 4.2 depicts the profiles of $H^{\prime}$ for $W_{e}=0.2$ and various values of $\gamma$. It can be observed that as the slip parameter $\gamma$ increases the values of $H^{\prime}$ near the wall decreases.

The Maclaurin series for $G(y)$ is given by

$$
G(y)=2 k \gamma \lambda y+k \lambda y^{2}+\frac{k}{3\left(1-W_{e} \gamma s\right)}\left[C+\gamma^{2} s \lambda-W_{e} \lambda\left(s+\frac{\gamma\left(1-\gamma^{2} s^{2}+W_{e} s^{2}\right)}{1-2 W_{e} \gamma s}\right)\right] y^{3},
$$

where $H^{\prime}(0)=\lambda$ are given in Table 4.1 for various values of $\gamma$ and $W_{e}$. 


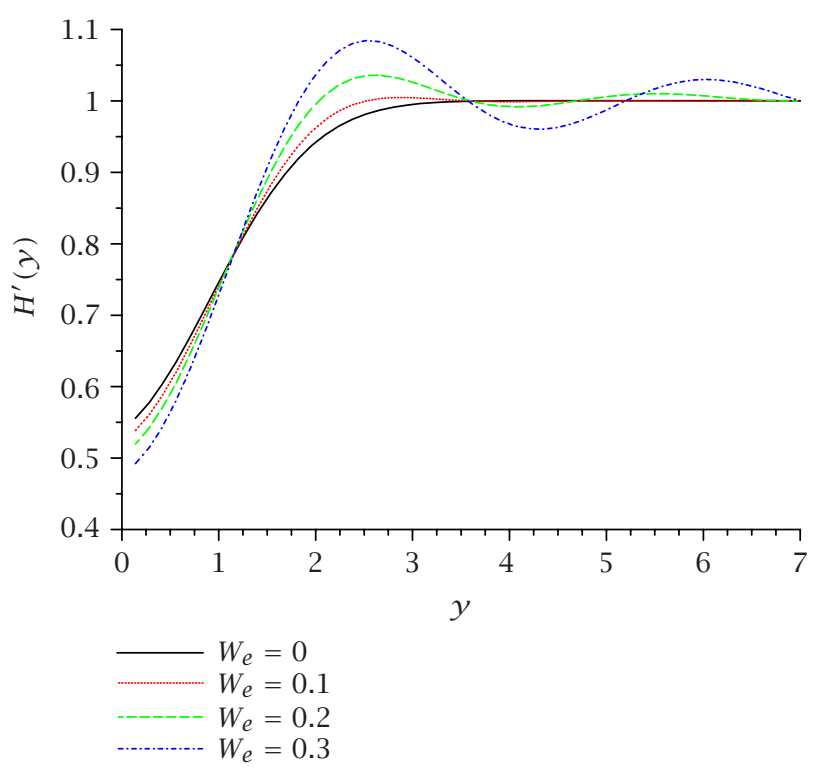

FigURE 4.1. Variation of $H^{\prime}(y)$ for $\gamma=1$ and various values of $W_{e}$.

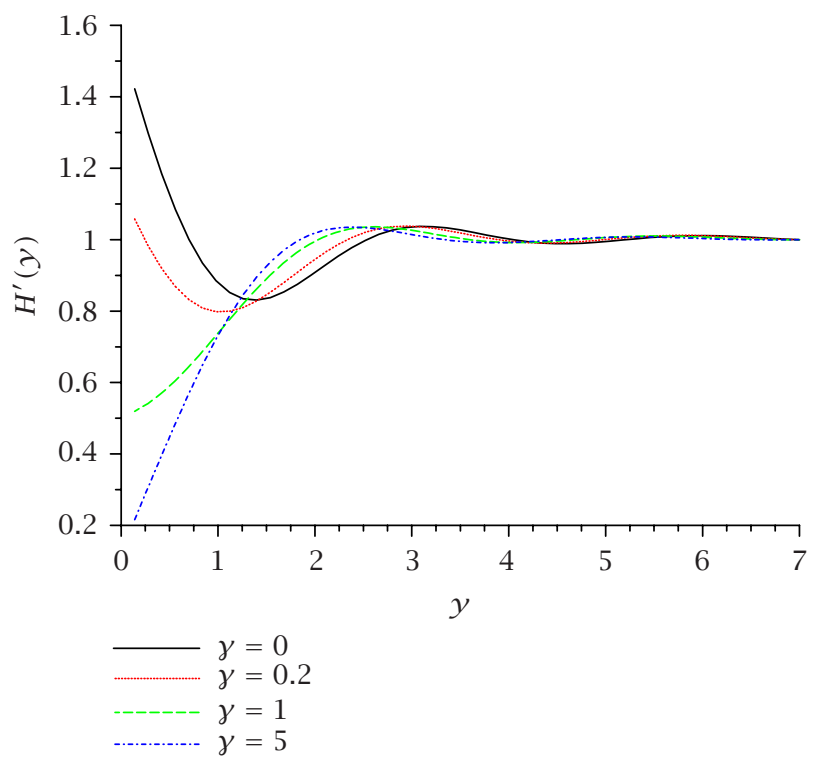

FIGURE 4.2. Variation of $H^{\prime}(y)$ for $W_{e}=0.2$ and various values of $\gamma$. 
5. Conclusions. The behavior of the Walters' B' fluid impinging on a rigid wall with slip was examined. The fluid impinges on the wall either orthogonally or obliquely. It was found that the effects of the slip condition and the viscoelasticity were to increase the velocity near the wall.

\section{REFERENCES}

[1] P. D. Ariel, A hybrid method for computing the flow of viscoelastic fluids, Internat. J. Numer. Methods Fluids 14 (1992), no. 7, 757-774.

[2] D. W. Beard and K. Walters, Elastico-viscous boundary-layer flows. I. Two-dimensional flow near a stagnation point, Proc. Cambridge Philos. Soc. 60 (1964), 667-674.

[3] C. Derek, D. C. Tretheway, and C. D. Meinhart, Apparent fluid slip at hydrophobic microchannel walls, Phys. Fluids 14 (2002), no. 3, L9-L12.

[4] J. M. Dorrepaal, An exact solution of the Navier-Stokes equation which describes nonorthogonal stagnation-point flow in two dimensions, J. Fluid Mech. 163 (1986), 141-147.

[5] J. M. Dorrepaal, O. P. Chandna, and F. Labropulu, The flow of a visco-elastic fluid near a point of re-attachment, Z. Angew. Math. Phys. 43 (1992), no. 4, 708-714.

[6] S. Goldstein, Modern Developments in Fluid Dynamics, Dover Publications, New York, 1965.

[7] K. Hiemenz, Die Grenzschicht an einem in den gleichformigen Flussigkeitsstrom eingetauchten geraden Kreiszylinder, Dingler's Polytech. J. 326 (1911), 321-410.

[8] M. N. Kogan, Rarefied Gas Dynamics, Plenum, New York, 1969.

[9] F. Labropulu, J. M. Dorrepaal, and O. P. Chandna, Viscoelastic fluid flow impinging on a wall with suction or blowing, Mech. Res. Comm. 20 (1993), no. 2, 143-153.

[10] C. L. M. Navier, Sur les lois du mouvement des fluids, Mem. Acad. R. Sci. Inst. Fr. 6 (1827), 389-440.

[11] K. R. Rajagopal, A. S. Gupta, and T. Y. Na, A note on the Falkner-Skan flows of a nonNewtonian fluid, Internat. J. Non-Linear Mech. 18 (1983), no. 4, 313-320.

[12] F. Sharipov and V. Seleznev, Data on internal rarefied gas flow, J. Phys. Chem. Ref. Data 27 (1998), no. 3, 657-706.

[13] F. Soltani and U. Yilmazer, Slip velocity and slip layer thickness in flow of concentrated suspensions, J. Appl. Polym. Sci. 70 (1998), no. 3, 515-522.

[14] J. T. Stuart, The viscous flow near a stagnation point when the external flow has uniform vorticity, J. Aero. Sci. 26 (1959), 124-125.

[15] K. J. Tamada, Two-dimensional stagnation point flow impinging obliquely on a plane wall, J. Phys. Soc. Japan 46 (1979), 310-311.

[16] K. Walters, Second-Order Effects in Elasticity, Plasticity and Fluid Dynamics, Pergamon, Oxford, 1964.

[17] C. Y. Wang, Stagnation flows with slip: exact solutions of the Navier-Stokes equations, Z. Angew. Math. Phys. 54 (2003), no. 1, 184-189.

F. Labropulu: Luther College-Mathematics, University of Regina, Regina, SK Canada S4S 0A2

E-mail address: fotni . 1abropulu@uregina.ca

I. Husain: Luther College-Mathematics, University of Regina, Regina, SK Canada S4S 0A2

E-mail address: igbal.husain@uregjn.ca

M. Chinichian: Luther College-Mathematics, University of Regina, Regina, SK Canada S4S 0A2

E-mail address: mazdav-coop@yahoo.com 


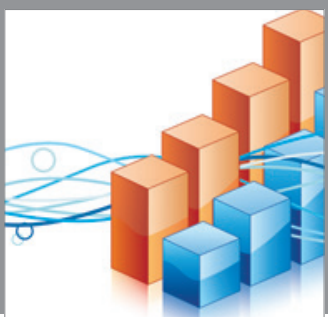

Advances in

Operations Research

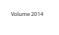

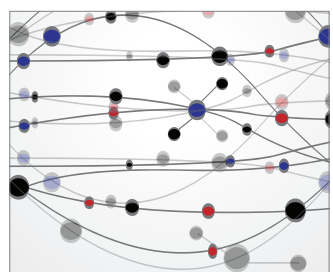

\section{The Scientific} World Journal
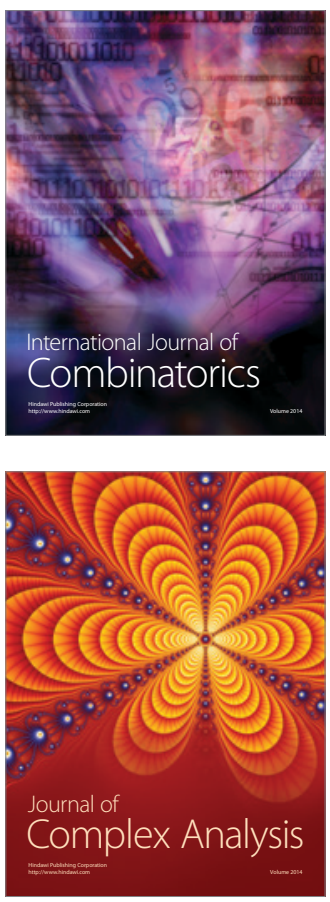

International Journal of

Mathematics and

Mathematical

Sciences
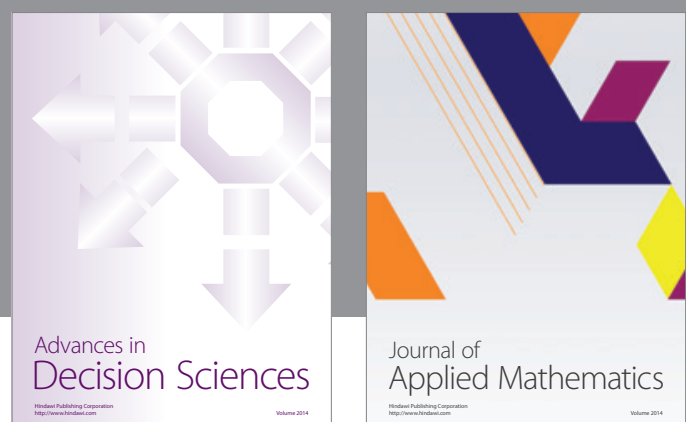

Journal of

Applied Mathematics
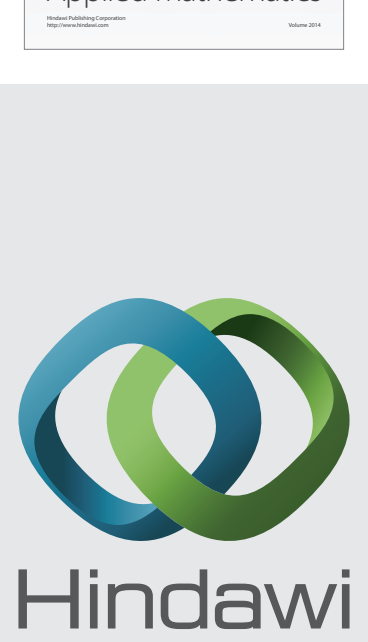

Submit your manuscripts at http://www.hindawi.com
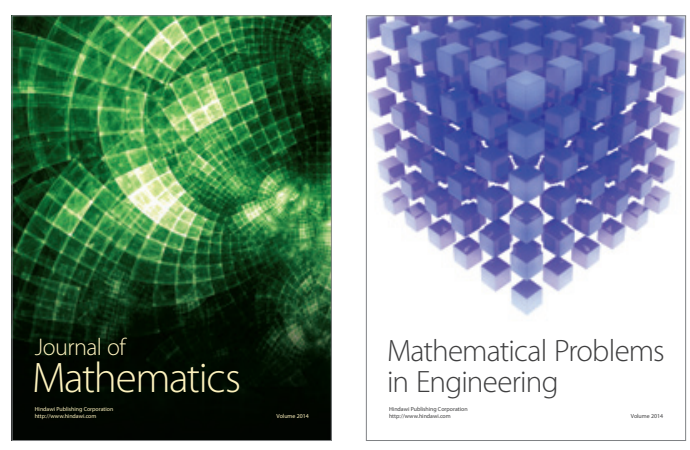

Mathematical Problems in Engineering
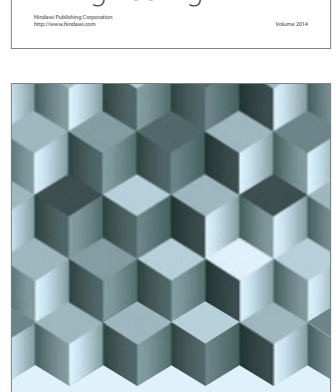

Journal of

Function Spaces
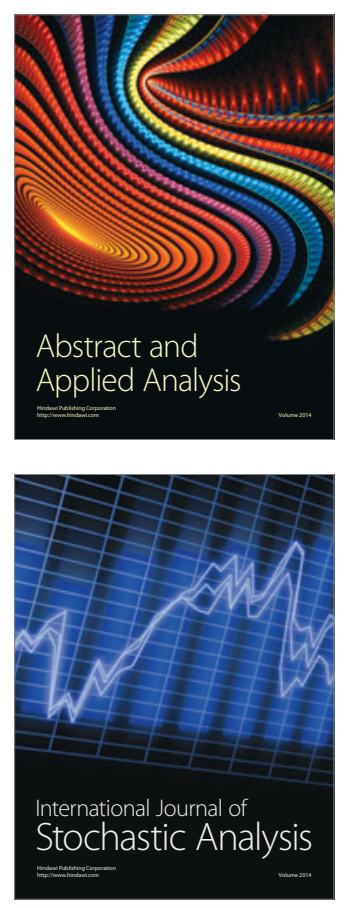

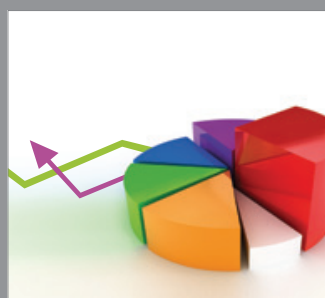

ournal of

Probability and Statistics

Promensencen
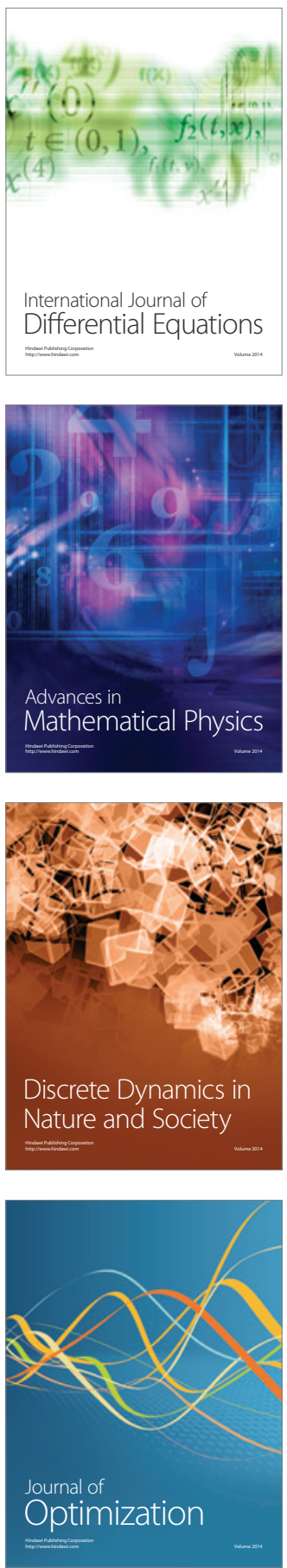